\title{
RATES OF MOUTH CANCER INCREASE TO ALL TIME HIGH
}

New statistics from Cancer Research UK show that mouth cancer rates are seeing a rapid increase ${ }^{1}$, with more than 7,300 Brits now being diagnosed with the disease each year.

The alarming findings show that around 20 people every day are being diagnosed with mouth cancer, equating to around one every 72 minutes - less time than it takes to play a game of rugby.

Mouth cancer is now the 10th most common cancer in men in the UK and 15th most common in women, overall mouth cancer is the 14th most common cancer in Britain but if current trends continue is on track to rapidly move up the list.

Mouth cancer in the UK has increased by around a third ( 34 per cent) in the last decade alone and by more than four-fifths ( 83 per cent) since the late 1970s.

The dramatic increase has been put down to changes in the prevalence of oral cancer risk factors such as alcohol consumption, tobacco use (smoking and smokeless) and human papilloma virus (HPV) infection, which can be transmitted through oral sex.

Speaking on the announcement Dr Nigel Carter OBE, Chief Executive of the British Dental Health Foundation, said: 'These findings are extremely worrying, especially when you consider that over 90 per cent of mouth cancer cases are entirely preventable.

'Our own research has revealed that one in seven ${ }^{2}$ remain unaware that we can get cancer in the mouth - this is very much where the problem lies. We simply are not aware enough of mouth cancer as a disease, let alone the risk factors and symptoms to do something about it.

'While there are more than twice as many mouth cancers in men than women, our study also found that men are far less likely to recognise the early warning signs of mouth cancer.

The research conducted by the oral health charity in aid of Mouth Cancer Action Month identified that women were around ten per cent more likely than men to associate lumps or swellings in the head and neck area and non-healing mouth ulcers to mouth cancer.

Mouth Cancer Action Month runs throughout November and is organised by the British Dental Health Foundation

and sponsored by Denplan. The charity campaign is aiming to raise awareness of the signs and symptoms of mouth cancer, in order to get more cases caught early enough to make a difference to the chances of survival.

'Early detection dramatically improves the chances of survival from 50 to 90 per cent so it is vital that if anybody, not just men, are able to spot anything unusual that they get examined straight away,' added Dr Carter.

'Dentists check for signs of mouth cancer during every examination; but a quarter of us are not aware of this this. Many of us also are unable to recognise what to look out for. It is important that we are alert for any changes that occur in the mouth and act quickly on them by seeking professional help.

'We are also urging everyone to ensure they make sure they visit their dentist regularly. One in ten of us admit that we haven't visited the dentist in the last two years, which is particularly concerning given the role early diagnosis plays on chances of beating cancer.

Mouth cancer can strike in a number of places, including the lips, tongue, gums and cheek. Given that early detection is so crucial for survival, it's extremely important that we all know what to look out for.

Be alert to mouth ulcers which do not heal within three weeks, red or white patches in the mouth and any unusual swellings or lumps in the head or neck area.

If you notice any of these, it is vital that we act quickly and seek the help and advice by visiting your dental practice or GP.

1. Cancer Research UK. Oral cancer statistics (2015). Available online at www.cancerresearchuk.org/healthprofessional/cancer-statistics/ statistics-by-cancer-type/oralcancer\#heading-Zero (accessed December 2015)

2. Research conducted on behalf of the British Dental Health Foundation by Atomik Research, September 2015. Sample size: 2,024 . $\begin{array}{ll}\text { Sample size: } & \text { 2,024. }\end{array}$ Sample size: Sample size: Sample size:

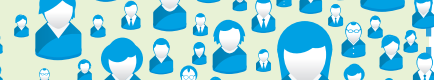

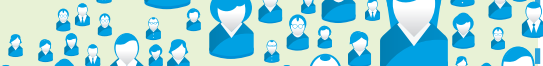

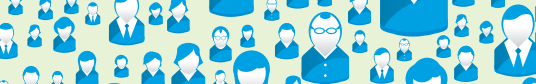

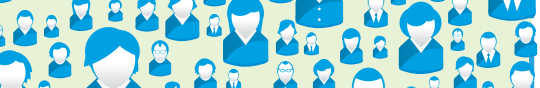
D. 2030830 2a 20

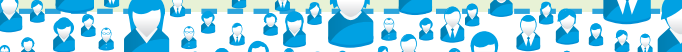

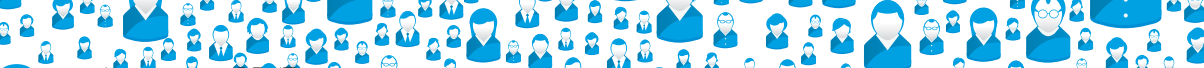

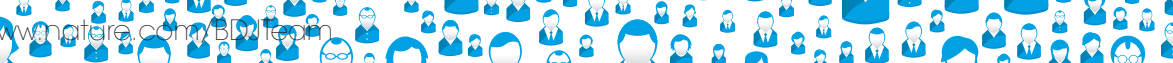

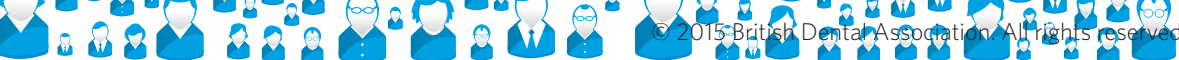

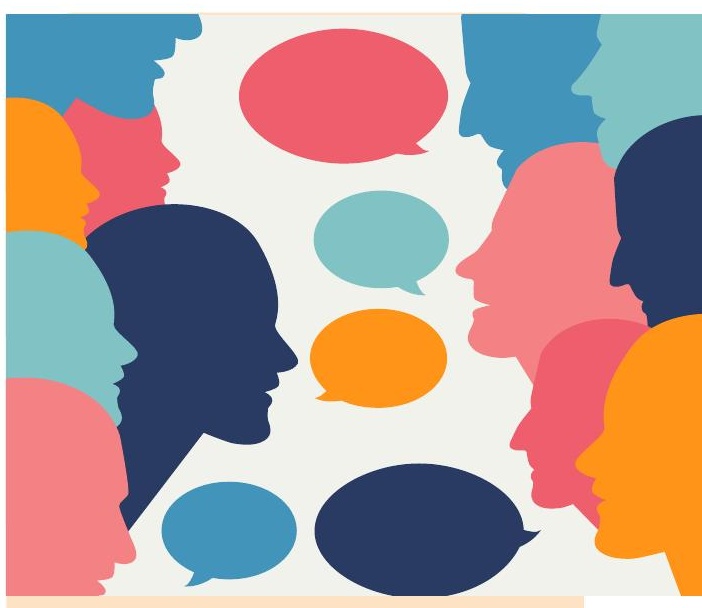

DENTISTS RELIEVED AT ENDTO IMPASSE ON JUNIOR

The British Dental Association (BDA) has responded to news that government appears to have relented in its bid to impose a new contract on hospital dentists and medics.

News comes as the British Medical Association (BMA) was set for its first day of industrial action. The BDA has just completed its own ballot on industrial action, with 100 per cent of voters backing moves to join medics on the their second planned day of industrial action which was set for Tuesday 8th December.

The dentists are now joining medics in suspending plans for industrial action until further notice.

Mick Armstrong, Chair of the British Dental Association, said: 'Dentists have never taken industrial action before. Our members were never seeking to be pioneers, they just want what's best for their patients and for practitioners, so we are pleased to see that $11^{\text {th }}$ hour negotiations are finally making headway.

'The results of our own ballot were unambiguous. However we have always believed that genuine dialogue could achieve more than industrial action, and we are satisfied to suspend all planned action indefinitely.

'Government has helped break the deadlock by withdrawing its threat to impose a flawed contract. Like our medical colleagues, dentists never wanted to see this dispute get so far. Now that the single biggest obstacle has been removed we are cautiously optimistic that real progress is possible. 